\author{
SANDIA REPORT \\ SAND2008-8053 \\ Unlimited Release \\ Printed December 2008
}

\title{
Software and Codes for Analysis of Concentrating Solar Power Technologies
}

\author{
Clifford K. Ho
}

Prepared by

Sandia National Laboratories

Albuquerque, New Mexico 87185 and Livermore, California 94550

Sandia is a multiprogram laboratory operated by Sandia Corporation,

a Lockheed Martin Company, for the United States Department of Energy's

National Nuclear Security Administration under Contract DE-AC04-94AL85000.

Approved for public release; further dissemination unlimited. 
Issued by Sandia National Laboratories, operated for the United States Department of Energy by Sandia Corporation.

NOTICE: This report was prepared as an account of work sponsored by an agency of the United States Government. Neither the United States Government, nor any agency thereof, nor any of their employees, nor any of their contractors, subcontractors, or their employees, make any warranty, express or implied, or assume any legal liability or responsibility for the accuracy, completeness, or usefulness of any information, apparatus, product, or process disclosed, or represent that its use would not infringe privately owned rights. Reference herein to any specific commercial product, process, or service by trade name, trademark, manufacturer, or otherwise, does not necessarily constitute or imply its endorsement, recommendation, or favoring by the United States Government, any agency thereof, or any of their contractors or subcontractors. The views and opinions expressed herein do not necessarily state or reflect those of the United States Government, any agency thereof, or any of their contractors.

Printed in the United States of America. This report has been reproduced directly from the best available copy.

Available to DOE and DOE contractors from

U.S. Department of Energy

Office of Scientific and Technical Information

P.O. Box 62

Oak Ridge, TN 37831

Telephone: $\quad$ (865) 576-8401

Facsimile: (865) 576-5728

E-Mail: reports@adonis.osti.gov

Online ordering: http://www.osti.gov/bridge

Available to the public from

U.S. Department of Commerce

National Technical Information Service

5285 Port Royal Rd.

Springfield, VA 22161

Telephone: $\quad$ (800) 553-6847

Facsimile: (703) 605-6900

E-Mail: $\quad$ orders@ntis.fedworld.gov

Online order: $\quad$ http://www.ntis.gov/help/ordermethods.asp?loc=7-4-0\#online

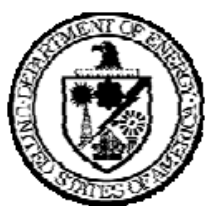


SAND2008-8053

Unlimited Release

Printed December 2008

\title{
Software and Codes for Analysis of Concentrating Solar Power Technologies
}

\author{
Clifford K. Ho \\ Solar Technologies Department \\ Sandia National Laboratories \\ P.O. Box 5800 \\ Albuquerque, NM 87185
}

\begin{abstract}
This report presents a review and evaluation of software and codes that have been used to support Sandia National Laboratories' concentrating solar power (CSP) program. Additional software packages developed by other institutions and companies that can potentially improve Sandia's analysis capabilities in the CSP program are also evaluated. The software and codes are grouped according to specific CSP technologies: power tower systems, linear concentrator systems, and dish/engine systems. A description of each code is presented with regard to each specific CSP technology, along with details regarding availability, maintenance, and references. A summary of all the codes is then presented with recommendations regarding the use and retention of the codes. A description of probabilistic methods for uncertainty and sensitivity analyses of concentrating solar power technologies is also provided.
\end{abstract}




\section{Acknowledgments}

The author thanks Greg Kolb, Chuck Andraka, Vicente Romero, Rich Diver, and Cheryl Ghanbari for providing documentation and other historical information regarding the codes that were evaluated in this report.

Sandia is a multiprogram laboratory operated by Sandia Corporation, a Lockheed Martin Company for the United States Department of Energy's National Nuclear Security Administration under contract DE-AC04-94AL85000. 


\section{Contents}

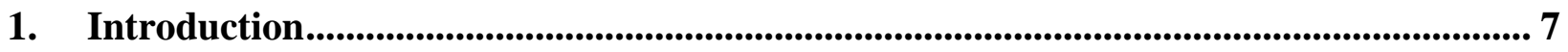

2. Power Tower Systems...............................................................................................................8 8

2.1 Optical Design and Performance of Heliostat Fields................................................. 9

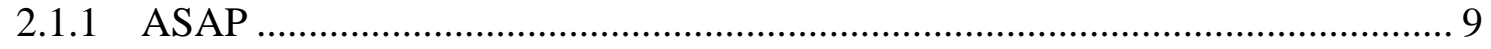

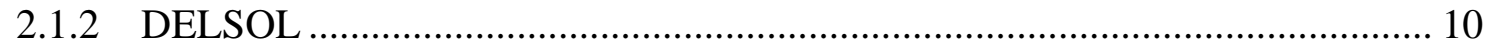

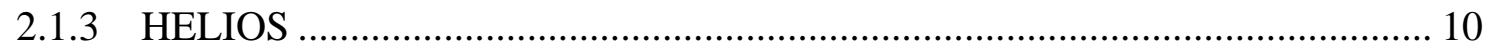

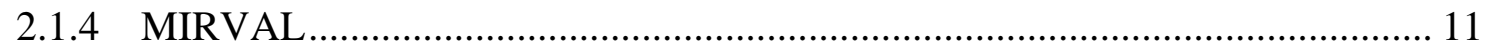

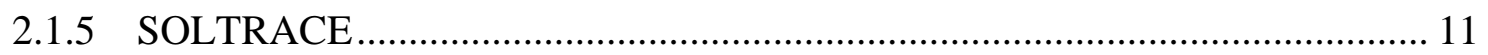

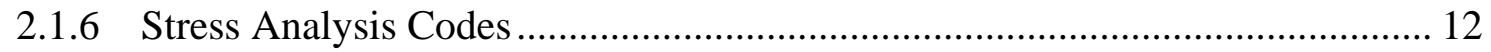

2.2 Central Receiver Performance ....................................................................... 12

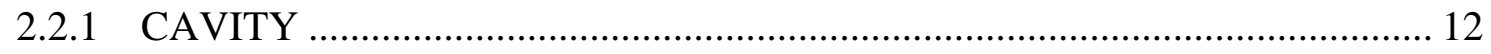

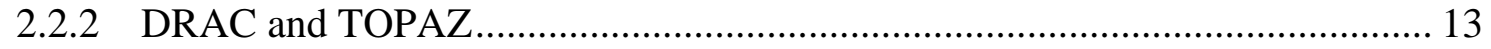

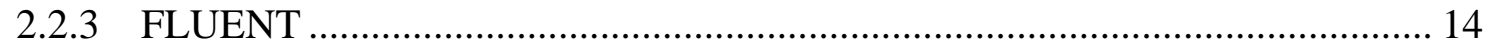

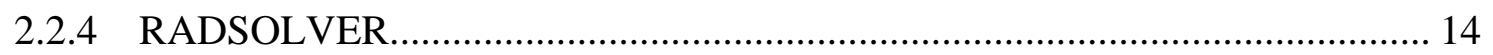

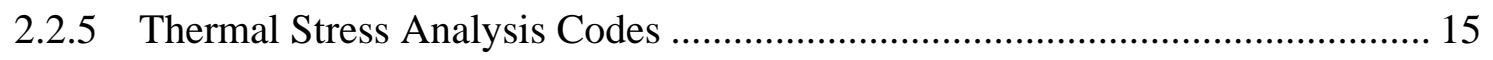

2.3 Heat Transfer Fluid (HTF) Transport, Exchange, and Storage ................................ 16

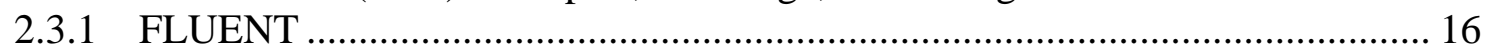

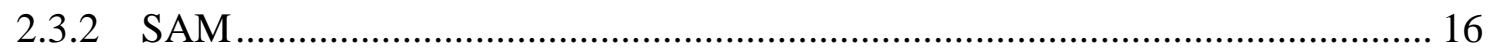

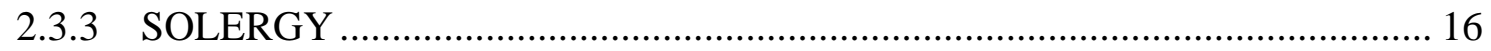

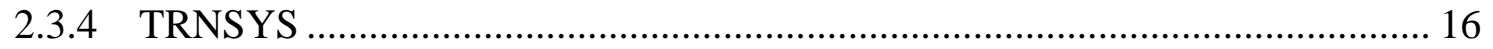

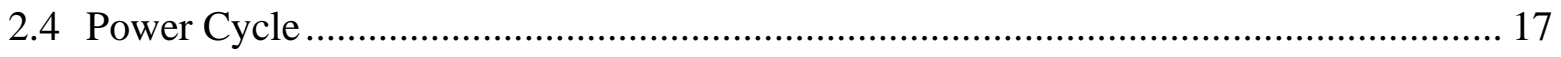

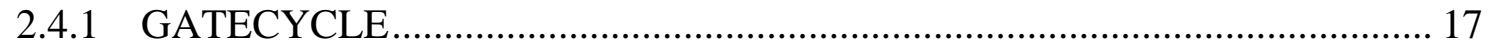

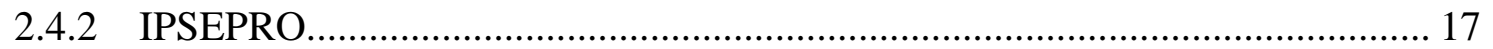

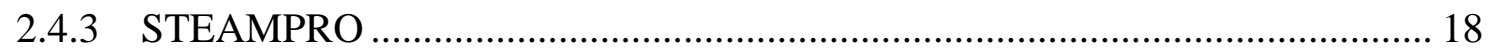

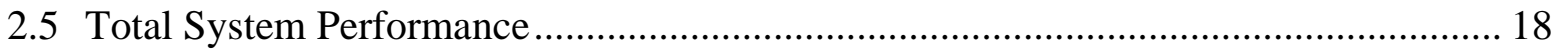

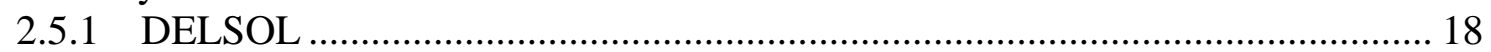

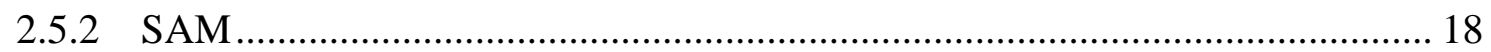

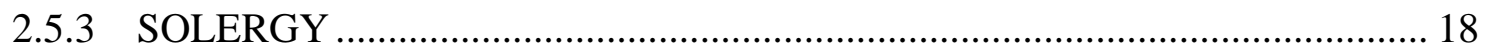

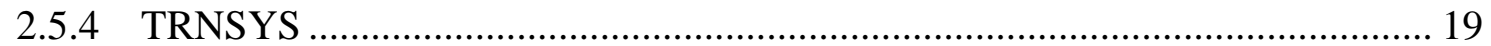

3. Linear Concentrator Systems .............................................................................. 19

3.1 Solar Collectors (Troughs and Linear Reflectors) ................................................. 21

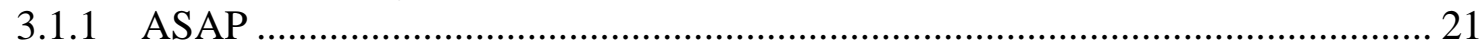

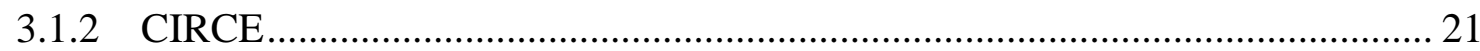

3.1.3 FLUENT .......................................................................................... 21

3.1.4 SOLTRACE ............................................................................................ 21

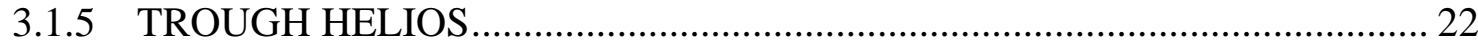

3.2 Heat Transfer Fluid (HTF) Transport, Exchange, and Storage ................................. 22

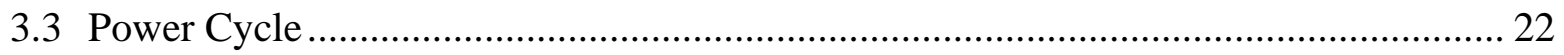

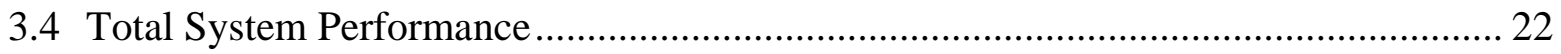

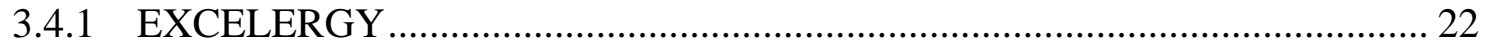




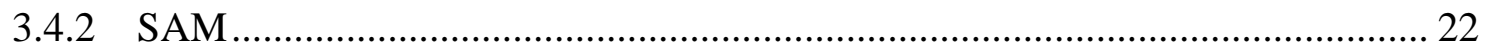

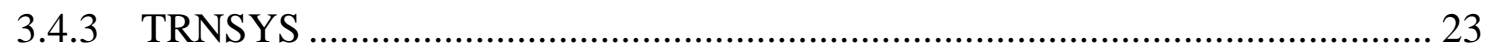

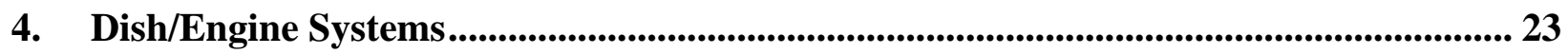

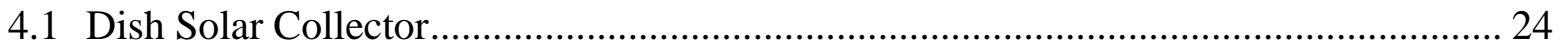

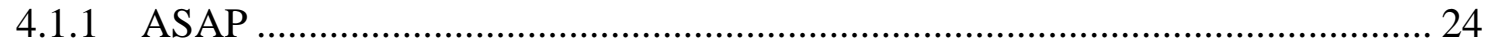

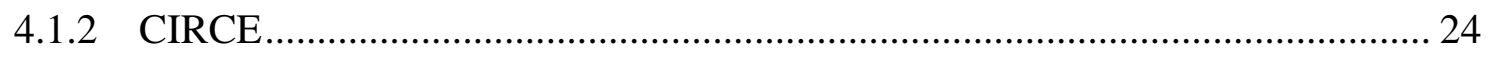

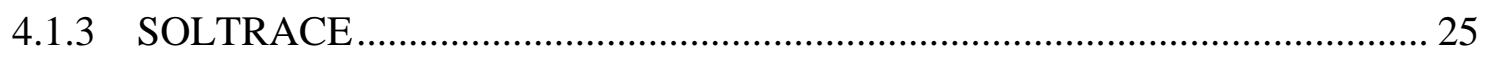

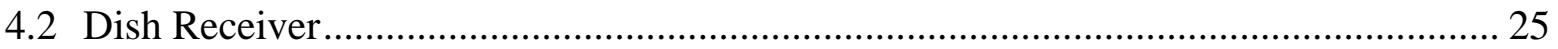

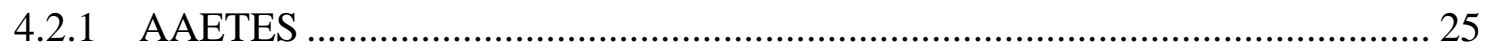

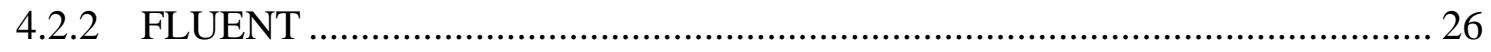

4.3 Dish Field System Performance......................................................................... 26

4.3.1 Dish Field Systems Model ...................................................................... 26

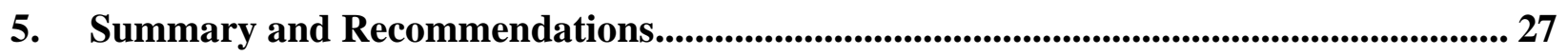

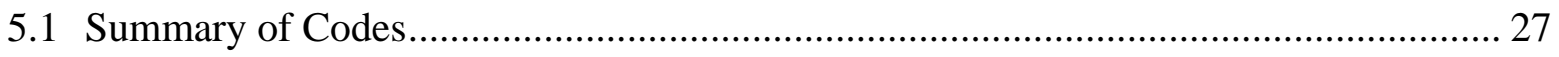

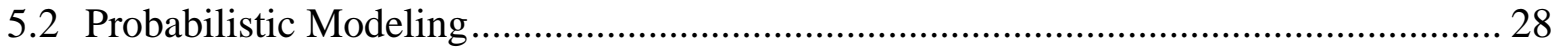

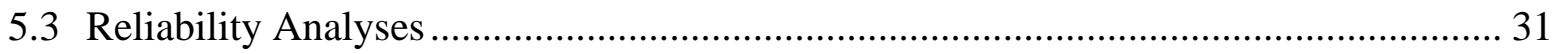

5.4 Assertion of Copyright................................................................................... 32

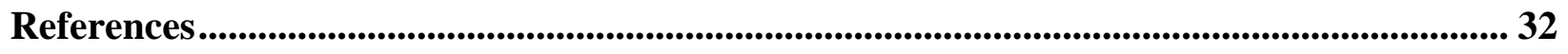




\section{Introduction}

This report presents a summary of models and software that can be used to analyze different concentrating solar power (CSP) technologies, which include power tower systems, linear concentrator systems (e.g., parabolic trough), and dish/engine systems. The list of models and software is by no means exhaustive; the intent was to compile a list of existing codes and tools at Sandia National Laboratories to identify gaps and/or redundancies in our analysis capabilities. Another objective was to identify which codes should be modernized (some are over 20-30 years old) and possibly combined. Other codes developed by the National Renewable Energy Laboratory (NREL) and commercial entities are also identified, but the list is limited to software that have been used or considered by Sandia’s Solar Technologies Department.

The models and codes can be grouped according to a "modeling pyramid," which describes a natural hierarchy for modeling complex systems (Figure 1). At the top, total system models are used to evaluate overall performance metrics such as levelized energy cost or power output. These total system models rely on input from more detailed process models that provide information regarding the performance of individual components within the total system. The process models require input parameters and distributions (for uncertainty and sensitivity analyses) that are acquired through various means such as testing, literature, surveys, and/or professional judgment. This modeling pyramid is often used as the framework for modeling complex systems because it provides a logical flow and organization of the information and modeling activities. In addition to passing information up from the detailed process models and parameters, the framework calls for information being passed down from the top to assist in prioritizing modeling and characterization efforts in areas that have been shown in the models to significantly impact the relevant cost and performance metrics (see Section 5.2 for more details).

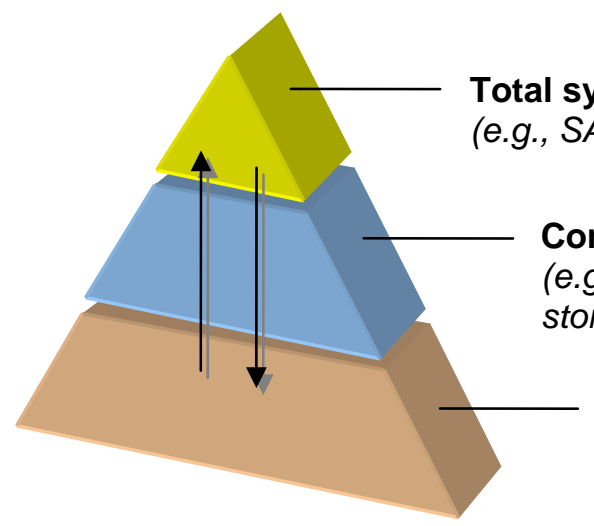

Component and process models

(e.g., collector/reflector optics, receiver performance, thermal storage processes, power output)

Input parameters and distributions

(e.g., geometry, reflectivity, solar radiation, temperature, flow rates, efficiencies, costs )

Figure 1. Illustration of the "modeling pyramid."

In the following sections, codes are grouped and identified according to each of the three CSP technologies, as well as categories within the modeling pyramid. A brief overview of each CSP technology is provided, followed by a description of codes that can be used to address the major components of each CSP technology. References for each code are also provided and hyperlinked to the appropriate document or web site, when available. 


\section{Power Tower Systems}

Power tower systems consist of a field of large, nearly-flat mirror assemblies (heliostats) that track the sun and focus the sunlight onto a receiver on top of a tower. In a typical configuration, a heat-transfer fluid such as water/steam or molten-nitrate salt is heated in the receiver and used to power a conventional steam-turbine power cycle to generate electricity (see Figure 2 and Figure 3). Excess thermal energy can be stored during daylight hours to allow operation of the steam turbine during non-solar hours. An advantage of power tower systems over linear concentrator systems is that higher temperatures can be achieved in the working fluid. Higher temperatures can lead to a lower-cost storage system. However, heliostats for power tower systems must each have their own dual-axis control as opposed to single-axis control for an array of mirrors in the linear concentrator systems.

Software and codes for the analysis of power tower systems were evaluated in the following component areas:

- $\quad$ Optical Design and Performance of Heliostat Fields

- Central Receiver Performance

- $\quad$ Heat Transfer Fluid (HTF) Transport, Exchange, and Storage

- Power Cycle

- Total System Performance

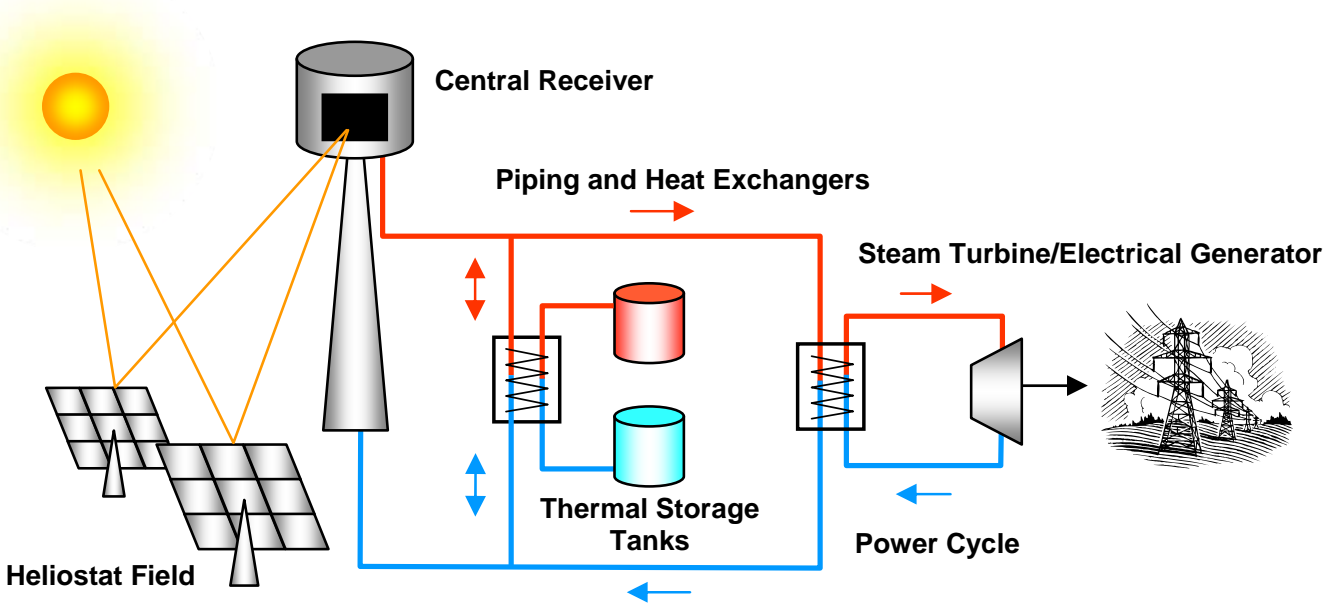

Figure 2. Illustration of a power tower system. An indirect storage system is depicted. At the Solar Two plant shown in Figure 3, a direct storage system was used. 


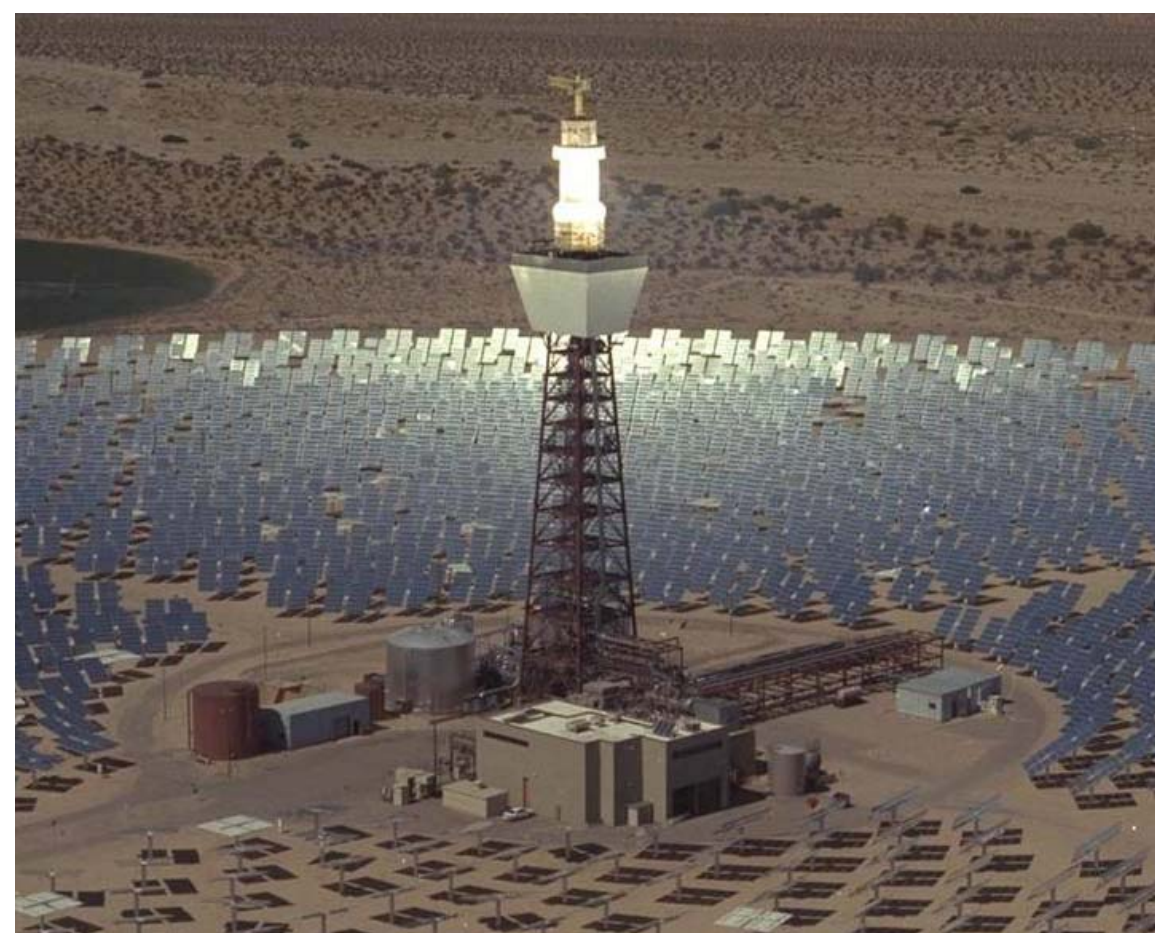

Figure 3. Photo of Solar Two power tower plant in operation in Daggett, CA (photo from Sandia National Laboratories, photo 2897).

\subsection{Optical Design and Performance of Heliostat Fields}

\subsubsection{ASAP}

\section{Description}

ASAP is commercial ray-tracing software that performs optical simulations of various geometries and systems. It renders system geometry, ray traces, and light sources, and it models visible, ultraviolet, and infrared radiation. It can optimize optical systems with an optimization interface, and it can import geometry data from SolidWorks via an IGES (Initial Graphics Exchange Specification) translator. The directional dependence of the sun's irradiation can be modeled, and a random or defined slope error for the mirror surface can be implemented along with reflection, refraction, scattering, and absorption with wavelength dependency. The flux distribution reflected from solar collectors can only be projected on planar surfaces currently, but the next version will allow conformal mapping of the flux distribution on non-planar surfaces. ASAP is also planning to integrate its software directly within SolidWorks.

Availability and Maintenance

ASAP is maintained and distributed by Breault Research (see links below).

References

- www.breault.com/software/asap.php 
- Examples of solar parabolic trough and dish systems using ASAP: http://www.breault.com/multimediagallery.php?catTypeID $=2 \&$ catID $=89 \&$ mode=category $)$

\subsubsection{DELSOL}

\section{Description}

DELSOL is a performance and design code that includes optical and economic analyses. An analytical Hermite polynomial expansion/convolution-of-moments method is used to predict flux images from the heliostats in a computationally efficient manner (typically much faster than either MIRVAL or HELIOS). The code accounts for variations in insolation, cosine forshortening, shadowing and blocking, and spillage, along with atmospheric attenuation, mirror and receiver reflectivity, receiver radiation and convection, and piping losses. The code can be used to evaluate the system levelized energy cost and optimize the field layout, receiver dimensions, and tower height based on these costs. The code is written in FORTRAN77, and input to the code is entered via user-specified text files.

\section{Availability and Maintenance}

DELSOL is still used by staff at Sandia and several industrial companies, but active maintenance and support for DELSOL is lacking.

\section{References}

- Dellin, T.A. and M.J. Fish, User's Manual for DELSOL: A Computer Code for Calculating the Optical Performance, Field Layout and Optimal System Design for Solar Central Receiver Plants, Sandia National Laboratories, Livermore, CA, SAND79-8215.

- Kistler, B.L., 1987, A User's Manual for DELSOL3: A Computer Code for Calculating the Optical Performance and Optimal System Design for Solar Thermal Central Receiver Plants, Sandia National Laboratories, Livermore, CA, SAND86-8018 (10 MB).

- Falcone, P.K., 1986, A Handbook for Solar Central Receiver Design, Sandia National Laboratories, Livermore, CA, SAND86-8009 (86 MB), p. C-9.

\subsubsection{HELIOS}

\section{Description}

HELIOS uses cone optics to evaluate the solar flux density from fields ranging from 1 to 559 individual heliostats (or cells with multiple heliostats). Parabolic dish and other collector shapes can also be evaluated with HELIOS. The code accounts for shadowing, blocking, declination of the sun, earth orbit eccentricity, molecular and aerosol scattering, atmospheric refraction, angular distribution of incoming solar rays, reflectivity, shapes of focused facets, and error distributions in the surface curvature, aiming, facet orientation, and shadowing and blocking. Input to the code is entered via user-specified text files. 
Availability and Maintenance

HELIOS is still used by staff at Sandia, but the original developers are no longer at Sandia. The code does not appear to be actively maintained.

\section{References}

- Vittitoe, C.N. and F. Biggs, 1981, User's Guide to HELIOS : Part 1, Introduction and Code Input. A Computer Program for Modeling the Optical Behavior of Reflecting Concentrators, Sandia National Laboratories, Albuquerque, NM, SAND81-1180 and SAND81-1562 (Part 3: Appendices).

- Falcone, P.K., 1986, A Handbook for Solar Central Receiver Design, Sandia National Laboratories, Livermore, CA, SAND86-8009 (86 MB), p. C-4.

\subsubsection{MIRVAL}

\section{Description}

MIRVAL is a Monte Carlo ray-tracing program that calculates field efficiencies and flux maps for individual heliostats and central receiver systems. It accounts for shadowing, blocking, heliostat tracking, angular distribution of incoming solar rays, scattering, attenuation between the heliostats and receiver, reflectivity, aiming strategies, and random errors in heliostat tracking and conformation of the reflective surface. Three partial receiver configurations and four heliostat types are included in the program. Input to the code is entered via user-specified text files.

Availability and Maintenance

The original authors of MIRVAL are no longer at Sandia, and the code is not being used at Sandia. The code is currently being used in Germany (DLR) and Israel (Weizman Institute).

References

- Leary, P.L. and J.D. Hankins, 1979, User's Guide for MIRVAL - A Computer Coe for Modeling the Optical Behavior of Reflecting Solar Concentrators, Sandia National Laboratories Livermore, CA, SAND77-8280 (microfiche and hard copy available at SNLL).

- Falcone, P.K., 1986, A Handbook for Solar Central Receiver Design, Sandia National Laboratories, Livermore, CA, SAND86-8009 (86 MB), p. C-1.

\subsubsection{SOLTRACE}

Description

SOLTRACE is a ray tracing model developed by the National Renewable Energy Laboratory (NREL) that can be used to analyze and design solar power optical systems. It can model parabolic trough collectors and other shapes and contours. The optical geometry can be modeled as a series of stages composed of optical elements with certain attributes including shape, contour, and optical quality. Results can be displayed and saved as scatter plots, flux maps, and 
performance graphs. The software implements a user-friendly GUI and logical steps for the problem definition.

Availability and Maintenance

A free download of SOLTRACE is available at the following website:

http://www.nrel.gov/csp/troughnet/models_tools.html\#soltrace

However, technical support is not provided for the model.

References

- Documentation for the SOTRACE software is included in the software download at: http://www.nrel.gov/csp/troughnet/models_tools.html\#soltrace

\subsubsection{Stress Analysis Codes}

\section{Description}

The solar flux distribution reflected from heliostats can be affected by structural deformations caused by external forces such as gravity and wind. Commercial codes such as CosmosWorks ${ }^{\circledR}$ or ANSYS $^{\circledR}$ can be used to model the stress and displacements of the heliostat subjected to gravity and/or wind loads. A detailed geometric model of the receiver tubes needs to be developed and meshed. Appropriate boundary conditions (loads and constraints) are applied, and the codes solve the stress distribution and displacements using finite element analyses. CosmosWorks $^{\circledR}$ is integrated within SolidWorks, ${ }^{\circledR}$ which makes it convenient to use for geometries and systems already modeled in SolidWorks. ${ }^{\circledR}$

Availability and Maintenance

ANSYS $^{\circledR}$ and CosmosWorks ${ }^{\circledR}$ are commercially maintained and sold.

References

- $\quad$ ANSYS $^{\circledR}:$ www.ansys.com

- $\operatorname{CosmosWorks}{ }^{\circledR}:$ www.cosmosm.com

\subsection{Central Receiver Performance}

\subsubsection{CAVITY}

Description

CAVITY solves the energy balance equations for a solar cavity receiver and couples radiative exchange within the cavity to conduction and convection within the receiver tubes and working fluid. Radiative and convective losses are estimated. The user specifies the inlet and desired outlet fluid temperatures for the tubes, and the code calculates the flow rate and fluid temperatures as a function of position. Input to the code is entered via user-specified text files. 
Availability and Maintenance

CAVITY is no longer maintained.

References

- Sayers, D.D., 1985, CAVITY-A Computer Code to Couple Radiative Exchange in a Cavity-Type Receiver with the Conductive-Convective Exchange to the Working Fluid, Sandia National Laboratories, Livermore, CA, Internal Memorandum RS 8245/20.

- Falcone, P.K., 1986, A Handbook for Solar Central Receiver Design, Sandia National Laboratories, Livermore, CA, SAND86-8009 (86 MB), p. C-15.

\subsubsection{DRAC and TOPAZ}

Description

DRAC is a driver program for TOPAZ, which simulated one-dimensional fluid flow in pipes with both steady and transient heat and mass transfer. Time-dependent incident heat-flux profiles and flow rate changes can be specified, and radiative and convective losses are included. Tube wall and fluid temperatures are calculated for flow in a single tube. Input to the code is entered via user-specified text files. Although Falcone (1986, p. C-13) states that TOPAZ can treat both incompressible (e.g., molten salt and liquid sodium) and compressible fluids (e.g., air, $\mathrm{He}$, and steam), the author of the code recently stated that TOPAZ is primarily a gas flow and transport code, and additional modifications would be required to treat incompressible fluids (William S. Winters, personal communication, 10/15/2008). In addition, a new code, called NETFLOW, has replaced both DRAC and TOPAZ.

\section{Availability and Maintenance}

DRAC and TOPAZ are no longer maintained. They have been replaced with NETFLOW. However, NETFLOW is primarily a compressible gas dynamics code. Additional modifications would be required to apply it to relevant heat-transfer fluids used for solar applications.

\section{References}

- Winters, W.S., 1983, DRAC—A User Friendly Computer Code for Modeling Transient Thermohydraulic Phenomena in Solar Receiver Tubing, Sandia National Laboratories, Livermore, CA (SAND82-8744).

- Winters, W.S., 1987, TOPAZ-The Transient One-Dimensional Pipe Flow Analyzer: An Update on Code Improvements and Increased Capabilities, Sandia National Laboratories, Livermore, CA (SAND87-8225).

- Falcone, P.K., 1986, A Handbook for Solar Central Receiver Design, Sandia National Laboratories, Livermore, CA, SAND86-8009 (86 MB), p. C-13. 


\subsubsection{FLUENT}

\section{Description}

FLUENT is a computational fluid dynamics code that can simulate laminar and turbulent fluid flow, conduction, convection, radiation, and conjugate heat transfer with multiphase flow and transport. FLUENT solves the equations of continuity, momentum, and energy for each finitevolume cell in the discretized domain. FLUENT includes several different radiation transfer models, including a discrete ordinates radiation model that accounts for gray or non-gray (up to 10 bands) surfaces with reflection (specular, diffuse, or combined), refraction, absorption, scattering, and emission with participating media. FLUENT can be generally applied to various components of central receiver systems, but a detailed geometric model of the system must be developed and meshed (GAMBIT is the geometry and meshing program that is part of FLUENT). Graphical user interfaces are available in both GAMBIT and FLUENT to set up and run the model. FLUENT models of the solid particle receiver (SPR) have been developed with good comparisons to data. The SPR problem involved solar irradiation through the aperture, two-phase flow (air was the continuous phase, solid particles were the discrete phase) with twoway turbulent fluid interaction, convection and radiation within the receiver, conduction within the walls, and convective and radiative heat loss external to the receiver.

\section{Availability and Maintenance}

FLUENT is a commercial code owned and maintained by ANSYS, Inc. (www.fluent.com). Annual licenses cost between $\sim \$ 10,000$ and $\$ 20,000$ depending on the number of licenses purchased.

\section{References}

- See www.fluent.com

\subsubsection{RADSOLVER}

\section{Description}

RADSOLVER calculates the radiation energy transfer within arbitrarily shaped solar cavity receivers. It accounts for non-gray surfaces and accommodates wavelength-dependent radiative properties for emission and reflection using an arbitrary number of wavelength bands. RADSOLVER includes thermal emission and reflection and absorption of thermal and solar radiation within zones defined for the cavity. Convection of air within the cavity is neglected. Input to the code is entered via user-specified text files.

\section{Availability and Maintenance}

This code does not appear to be maintained, and it has not been used in many years.

\section{References}

- Abrams, M., 1981, RADSOLVER-A computer Program for Calculating SpectrallyDependent Radiative Heat Transfer in Solar Cavity Receivers, Sandia National Laboratories, Livermore, CA (SAND81-8248). 
- Falcone, P.K., 1986, A Handbook for Solar Central Receiver Design, Sandia National Laboratories, Livermore, CA, SAND86-8009 (86 MB), p. C-11.

\subsubsection{Thermal Stress Analysis Codes}

\section{Description}

Thermal stress analyses of receiver tubes can be performed to determine the peak allowable solar flux on the receiver. Commercial codes such as CosmosWorks ${ }^{\circledR}$ or ANSYS $^{\circledR}$ can be used to evaluate transient or cyclic stress from radiative heating/cooling cycles with heat loss to a heat transfer fluid. A detailed geometric model of the receiver tubes needs to be developed and meshed. Appropriate thermal and structural boundary conditions are applied, and the codes solve the stress distribution and displacements using finite element analyses. CosmosWorks ${ }^{\circledR}$ is integrated within SolidWorks, ${ }^{\circledR}$ which makes it convenient to use for geometries and systems already modeled in SolidWorks. ${ }^{\circledR}$

TBRD (Transient Behavior Receiver Device) is a dynamic simulation model that Sandia developed for the Solar Two receiver. It was used to analyze tube strains during cloud transients and to develop a receiver control system to maintain tube strains within acceptable limits. The ordinary differential equations that describe the conservation of mass, energy, and momentum within the receiver were solved with the SYSL Simulation Language.

Availability and Maintenance

ANSYS $^{\circledR}$ and CosmosWorks ${ }^{\circledR}$ are commercially maintained and sold. TBRD is no longer maintained.

References

- ANSYS $^{\circledR}:$ www.ansys.com

- CosmosWorks ${ }^{\circledR}: \underline{w w w \cdot c o s m o s m . c o m ~}$

TRBD:

- Kolb, G.J., 1992, Development of a Control Algorithm for a Molten-Salt Solar Central Receiver in a Cylindrical Configuration, in proceedings of the ASME Solar Energy Conference, Maui, HI, April 5-9, 1992, SAND91-2544C (640 KB)

- Kolb, G.J and D. Saluta, 1999, Automatic Control of the Solar Two Receiver, in proceedings of the ASME/Solar Specialists' Conference, Maui, HI, April 12-15, 1999, SAND99-1201C (441 KB).

- Kolb, G.J. and ESSCOR Corporation, 1989, Dynamic Simulation of a Molten Salt Solar Receiver, SAND88-2895, Sandia National Laboratories, Albuquerque, NM, 92 p. 


\subsection{Heat Transfer Fluid (HTF) Transport, Exchange, and Storage}

\subsubsection{FLUENT}

FLUENT can be used to rigorously model subsystem components such as piping, heat exchangers, and storage systems. Hydraulics and conjugate heat transfer (with conduction, convection, and radiation) can be rigorously analyzed to evaluate heat transfer, mixing, and other processes in these subsystem components. See Section 2.2.3 for more details regarding FLUENT.

\subsubsection{SAM}

Description

SAM includes high-level models for piping heat loss and thermal storage, but these components are treated as "lumped" systems. Explicit models of spatial and temporal processes within these subsystem components are not included. See Section 3.4.2 for more information regarding SAM.

\subsubsection{SOLERGY}

\section{Description}

Solergy performs an energy balance on the entire system and accounts for heat losses in each component, including piping and storage thermal losses. See 2.5.1 for more details on SOLERGY.

\subsubsection{TRNSYS}

\section{Description}

TRYNSYS is a software platform that enables the user to model different transient systems using modular components. Each component represents a physical process or feature in the system, and components can be developed and added, as needed, to a system model. A component reads in a text-based input file and provides output through the solution of algebraic or differential equations. Components include solar thermal collectors (parabolic concentrating solar collector, flat plate solar collector), heat exchangers (counter-flow, cross-flow, parallel flow, shell-andtube, waste heat recover, etc.), thermal storage tanks (stratified, variable volume, etc.), hydraulics (pumps, pipes, values, etc.), controllers, and more. Specific processes can be modeled for subcomponents of the total system, and total-system performance analyses can also be performed. The software contains a GUI that allows drag-and-drop arrangement and editing of component icons. Post-processing via graphing and reporting are also included in the software.

\section{Availability and Maintenance}

TRNSYS was developed at the University of Wisconsin, Madison, and is maintained by several distributors, including researchers at the University of Wisconsin. Details can be found at http://sel.me.wisc.edu/trnsys/. 


\section{References}

- http://sel.me.wisc.edu/trnsys/

\subsection{Power Cycle}

System-level codes such as SAM (Section 3.4.2), SOLERGY (Section 2.5.1), and DELSOL (Section 2.1.2) contain simplified models of the power cycle. Inputs to these models typically consist of specifications for the turbine and thermal input, and the power generated from the system is calculated. Specific components of the power cycle (e.g., boiler, turbine, condenser) are not modeled explicitly. The following codes explicitly model each of the power-cycle components.

\subsubsection{GATECYCLE}

\section{Description}

GATECYCLE is commercial software that models the performance of Rankine, gas-turbine, and combined power cycles via mass and energy balances in each component. It includes component-level processes such as fouling, pressure losses, boiler operations, and cooling tower operations. Design and off-design performance can be simulated to evaluate potential system modifications. A graphical user interface is used to construct the power cycles and enter data.

Availability and Maintenance

GATECYCLE is maintained and distributed by GE (see link below).

References

- $\quad$ www.gepower.com/prod_serv/products/oc/en/opt_diagsw/gatecycle1.htm

\subsubsection{IPSEPRO}

\section{Description}

IPSEPRO is commercial software that contains a set of modules for simulating heat and mass balances in power plants and heating systems. The software can be used to predict design and off-design performance and estimate costs during conceptual design. IPSEPRO also allows the user to create new component models or new model libraries. A graphical user interface is used to build models and enter data.

Availability and Maintenance

IPSEPRO is maintained and distributed by SimTech Simulation Technology (see link below).

\section{References}

- $\quad$ www.simtechnology.com/IPSEpro/english/IPSEpro.php 


\subsubsection{STEAMPRO}

Description

STEAMPRO is commercial software that solves mass and energy balances to simulate the performance for Rankine-cycle steam power plants. Design criteria and inputs for system components are prescribed by the user. Similar to GATECYCLE, the user constructs a model by connecting appropriate building blocks via a graphical user interface.

Availability and Maintenance

STEAMPRO is maintained and distributed via Thermoflow, Inc. (see link below).

References

- $\quad$ www.thermoflow.com/ConvSteamCycle_STP.htm

\subsection{Total System Performance}

\subsubsection{DELSOL}

Description

As described in Section 2.1.2, DELSOL calculates the system levelized energy cost and optimizes the field layout based on these costs. However, only a few representative days each month is used in the overall analysis. Often, the solar flux output from DELSOL is used as input to SOLERGY for a more rigorous annual performance assessment. See Section 2.1.2 for availability and references.

\subsubsection{SAM}

Description

As described in Section 3.4.2, SAM is system-level software that can predict the performance and economics of parabolic trough systems. A power-tower model is under development by the University of Wisconsin that combines elements of DELSOL and TRNSYS.

Availability and Maintenance

SAM is maintained and freely distributed by NREL (see link below).

References

- https://www.nrel.gov/analysis/sam/

\subsubsection{SOLERGY}

\section{Description}

SOLERGY simulates the operation and annual power output of a solar thermal power plant. It utilizes actual or simulated weather data at time intervals as short as 3 minutes and calculates the net electrical energy output including parasitic power requirements over a 24-hour day. Factors include energy losses in each component of the system, delays incurred during start-up, weather conditions, storage strategies, and power limitations for each component. The original version of 
SOLERGY (Stoddard et al., 1987) required that the energy collected by the receiver subsystem be sent to thermal storage. The code was later modified to allow the collected energy to bypass storage for analysis of the Solar One power plant (Alpert and Kolb, 1988). The code is written in FORTRAN77, and input to the code is entered via user-specified text files.

\section{Availability and Maintenance}

SOLERGY is still used by staff at Sandia, but the code is primarily maintained by the individuals who use it.

\section{References}

- Stoddard, M.C., S.E. Faas, C.J. Chiang, and J.A. Dirks, 1987, SOLERGY—A Computer Code for Calculating the Annual Energy from Central Receiver Power Plants, Sandia National Laboratories, Livermore, CA, SAND86-8060 (6 MB).

- Alpert, D.J. and G.J. Kolb, 1988, Performance of the Solar One Power Plant as Simulated by the SOLERGY Computer Code, Sandia National Laboratories, Albuquerque, NM, SAND88-0321 (5 MB).

- Falcone, P.K., 1986, A Handbook for Solar Central Receiver Design, Sandia National Laboratories, Livermore, CA, SAND86-8009 (86 MB), p. C-10.

\subsubsection{TRNSYS}

Description

As described in Section 2.3.4, TRNSYS is capable of constructing total-system models by connecting predefined modular components or new model components defined by the user. Each component represents a physical process or feature in the system and can include solar thermal collectors, heat exchangers, thermal storage tanks, hydraulics, power cycles (new), and controllers. The software is based on a graphical user interface that allows drag-and-drop construction of the models. See Section 2.3.4 for availability and references.

\section{Linear Concentrator Systems}

Linear concentrator systems consist of a large field of mirrors that track the sun and focus the sunlight onto a linear receiver tube. The receiver tube contains a heat-transfer fluid that is heated by the sunlight and used to create steam, which is used in a conventional steam-turbine power cycle to generate electricity (see Figure 4). The receiver tube is usually contained in a larger clear tube that is evacuated so that convective heat losses are minimized within the vacuum chamber. Thermal energy storage can be implemented in linear concentrator systems so that excess thermal energy can be used to produce steam during non-solar hours. Linear concentrator systems currently fall into two different categories and can be characterized by their collector system: (1) parabolic troughs and (2) linear Fresnel reflectors (see Figure 5). Parabolic trough collector systems consist of a curved trough of mirrors with a linear receiver supported by each trough running along the length of the reflectors. Linear Fresnel reflectors consist of nearly flat reflectors that focus sunlight onto a linear receiver above and separate from the reflectors. Linear Fresnel reflector systems aim lower overall costs by sharing a receiver among several 
mirrors while maintaining a simple line-focus geometry with one axis for tracking. With linear Fresnel reflectors, the receiver is stationary, so fluid couplings are not required. Also, because the mirrors do not support the receiver, they are structurally simpler.

Software and codes for the analysis of parabolic trough systems have been categorized and evaluated in the following component areas:

- Solar Collectors (Troughs and Linear Reflectors)

- Heat Transfer Fluid (HTF) Transport, Exchange, and Storage

- Power Cycle

- Total System Performance

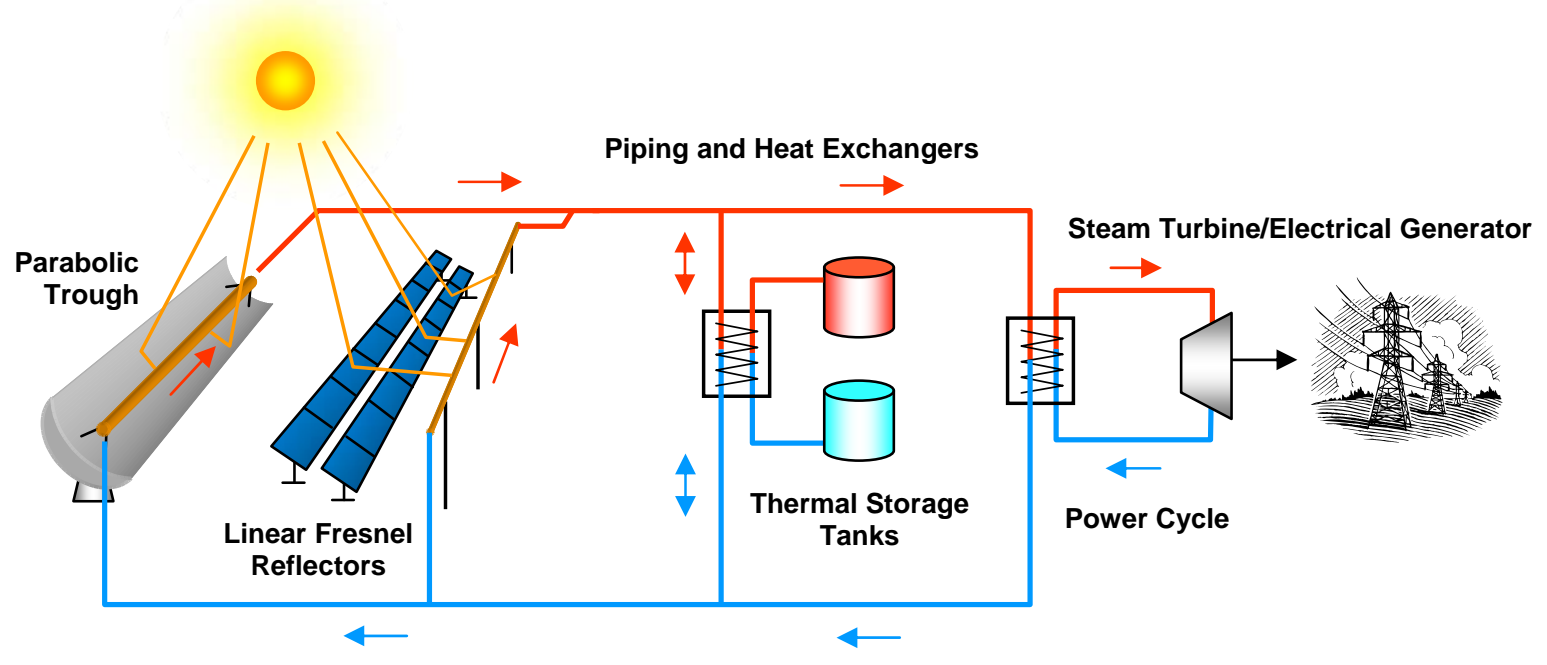

Figure 4. Illustration of linear concentrator system.
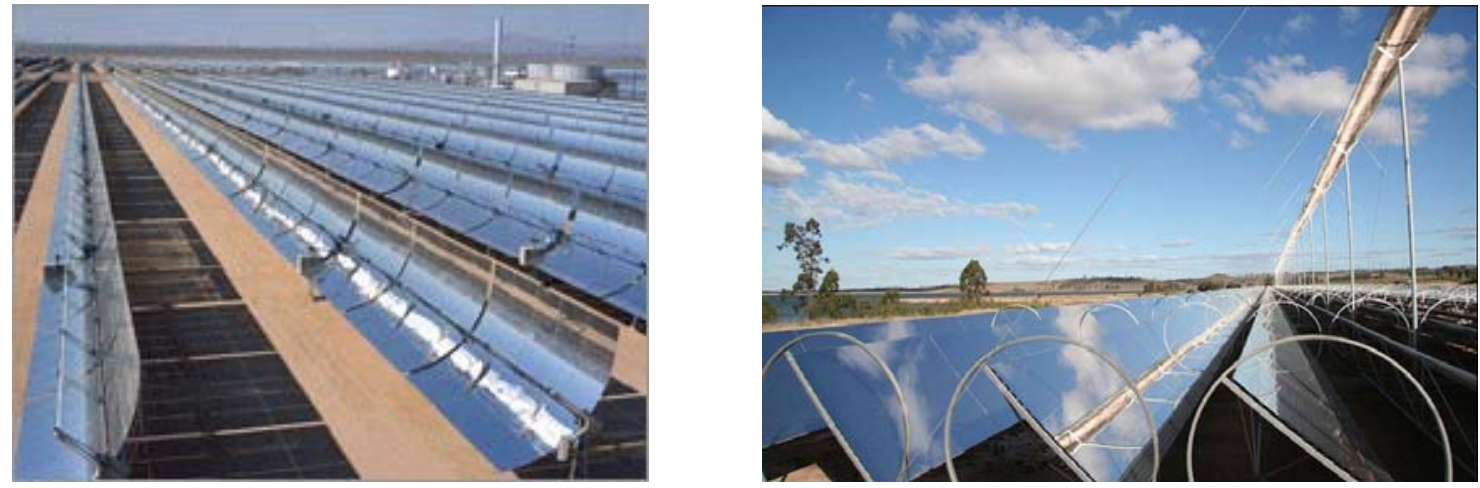

Figure 5. Parabolic trough (left) and linear Fresnel (right) collector systems (photos from http://en.wikipedia.org/wiki/Solar_thermal_energy). 


\subsection{Solar Collectors (Troughs and Linear Reflectors)}

\subsubsection{ASAP}

Description

ASAP is commercial software that can be used to model the optics of the parabolic trough or linear reflector systems. Currently, the flux distribution on the receiver can only be projected onto planar surfaces, but the next version should allow the flux distribution to be mapped onto non-planar surfaces. See Section 2.1.1 for more details regarding ASAP. An example of a parabolic trough collector was developed in ASAP and is available at the following site:

http://www.breault.com/multimedia-gallery.php?catTypeID=2\&catID=89\&mode=category

\subsubsection{CIRCE}

\section{Description}

Although CIRCE was originally developed for the analysis of point-focus dish collector systems (see Section 4.1.1), CIRCE can also be used to analyze the optics of parabolic trough and linear reflecting systems as well using USERDISH input, which requires a point-by-point tubular receiver. A need still exists for the ability to specify an analytic mirror shape, error profile, and horizontal analytic tubular receiver with integration capabilities. See Section 4.1.1 for more details regarding CIRCE.

\subsubsection{FLUENT}

Description

As described in Section 2.2.3, FLUENT is a computational fluid dynamics code that could be used to rigorously model the heat transferred to the linear receiver. Radiative flux distributions obtained from one of the optics codes described above can be used as boundary conditions in FLUENT to simulate the heat transfer and losses to and from the working fluid in the receiver. The annulus between the outer sleeve and the inner pipe can also be rigorously modeled. See Section 2.2.3 for more details regarding FLUENT.

\subsubsection{SOLTRACE}

\section{Description}

As described in Section 2.1.5, SOLTRACE is free software from NREL that can be used to model optical systems for solar power plants, including parabolic trough collectors. See Section 2.1.5 for more details regarding SOLTRACE. 


\subsubsection{TROUGH HELIOS}

Description

TROUGH HELIOS was developed by German collaborators from the original code, HELIOS (see Section 2.1.3). It models the solar flux distribution in parabolic trough systems.

Availability and Maintenance

The code does not appear to be maintained, and only one staff member at Sandia has an executable that runs on Windows 98 exclusively.

References

None available.

\subsection{Heat Transfer Fluid (HTF) Transport, Exchange, and Storage}

The codes used to analyze the heat transfer during fluid transport, exchange, and storage in linear concentrating systems are the same as those used for power-tower analyses (see Section 2.3).

\subsection{Power Cycle}

The codes used to analyze the power cycle for linear concentrating systems are the same as those used for power-tower analyses (see Section 2.4).

\subsection{Total System Performance}

\subsubsection{EXCELERGY}

EXCELERGY (Trough Excelergy) is an integrated design, cost, performance, and economics model developed by the National Renewable Energy Laboratory (NREL) to model solar thermal trough power plants. The model is contained in Microsoft Excel and was written in Visual Basic for Applications. Data can be entered into the spreadsheets to change the design, cost, operating strategy, or economic assumptions to determine the impact on the plant performance or economics. Hourly (or finer) time intervals can be used in the performance simulation model. An optimization run can also be conducted to evaluate the optimum solar field size versus thermal storage volume.

Availability and Maintenance

EXCELERGY is not maintained, but the trough performance and economic models have been transferred to SAM (see Section 3.4.2).

\subsubsection{SAM}

The Solar Advisor Model (SAM) was developed at the National Renewable Energy Laboratory (NREL); the trough performance and economic models are taken from the Excel-based model EXCELERGY developed at NREL (see Section 2.5.1). SAM provides a framework for analyzing system costs and performance of large photovoltaic and concentrating solar power 
(CSP) systems. The CSP model currently only includes parabolic trough systems for concentrating solar power, but it will soon add dish/engine and power-tower analysis capabilities. SAM combines hourly simulation models with performance, cost, and finance models to estimate energy output, costs, and cash flows. It includes built-in cost and performance models, and it can exchange data with external models developed in Microsoft Excel. The performance of each of the component models is based on correlations, analytical functions, or factors that describe the physical processes being modeled. Detailed modeling of the processes, including spatial and temporal variability within the subcomponents, is generally not included. In addition, detailed optical models of the solar collectors are not included.

Availability and Maintenance

SAM is maintained and freely distributed by NREL (see link below).

References

- $\quad$ https://www.nrel.gov/analysis/sam/

\subsubsection{TRNSYS}

\section{Description}

As described in Section 2.3.4, TRNSYS is capable of constructing total-system models by connecting predefined modular components or new model components defined by the user. Each component represents a physical process or feature in the system and can include solar thermal collectors, heat exchangers, thermal storage tanks, hydraulics, power cycles (new), and controllers. The software is based on a graphical user interface that allows drag-and-drop construction of the models. See Section 2.3.4 for availability and references.

\section{Dish/Engine Systems}

Dish/engine systems consist of dish-shaped collectors that track and focus the sun's radiation onto a receiver (see Figure 6). The receiver is part of a power conversion unit that includes an engine/generator. The receiver absorbs the reflected energy from the collector and heats a working fluid that is used to create mechanical energy through the movement of pistons. The movement of the pistons rotates a crankshaft that drives a generator to produce electricity. Thermal energy storage is not implemented in dish/engine systems. Dish/engine systems can produce high temperatures and efficient conversion to electricity, but many units are required to generate the same amount of electricity as centralized power tower and linear concentrator systems. Also, dish/engine units require a strong frame and tracking system to support the engine as part of the moving system, and dual-axis tracking is required.

Analyses of dish engines focus on optical analyses of the dish to maximize the radiant flux on the receiver. Issues affecting optical analyses include deformation (bending) of the dish support structure from gravity or wind, tracking accuracy, and discrete features of the facets. Codes are used to analyze the following components of dish engines: 
- Dish Solar Collector

- Dish Receiver

- Dish Field System Performance
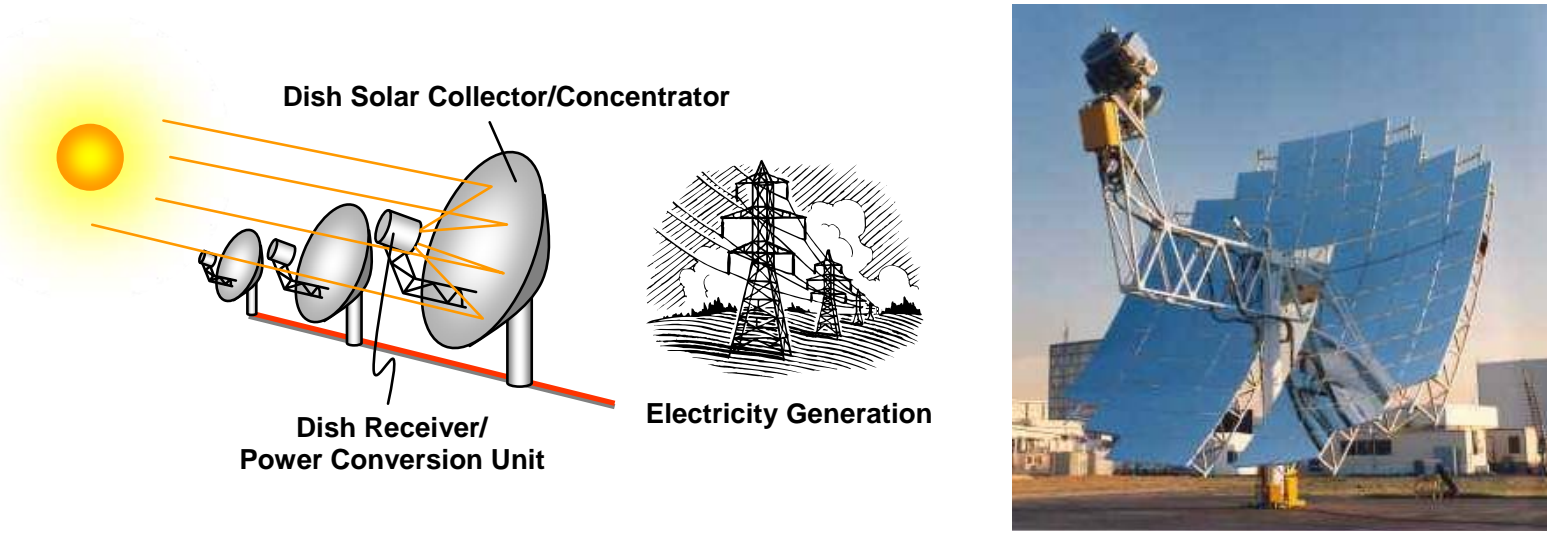

Figure 6. Illustration and photo of dish/engine system

(photo from http://en.wikipedia.org/wiki/Solar_thermal_energy).

\subsection{Dish Solar Collector}

\subsubsection{ASAP}

As described in Section 2.1.1, ASAP is capable of simulating the optics of various collector geometries, including dishes. The current version of ASAP, however, is only capable of simulating the reflected flux onto planar surfaces. The next version of ASAP should include the capability to map the flux distribution onto non-planar surfaces. See Section 2.1.1 for more details regarding ASAP. An example of a dish collector was developed in ASAP and is available at the following site:

http://www.breault.com/multimedia-gallery.php?catTypeID=2\&catID=89\&mode=category

\subsubsection{CIRCE}

\section{Description}

CIRCE is a computer code developed by Sandia National Laboratories that models the optics of solar concentrating collector systems. The code was derived from HELIOS (see Section 2.1.3) and initially used for point-focus dish concentrating collectors. Statistical methods are used to estimate the directional distribution of reflected rays from any point on the concentrator. Various geometries can be modeled (spherical, parabolic, flat, continuous, faceted, etc.), as well as the angular distribution of incident rays from the sun. Concentrator imperfections such as surface roughness and slope error can be implemented in the model to predict the flux distribution on the receiver target. Arbitrary target shapes can be modeled, including enclosures. The impacts of structural deformation caused by gravity and wind can be accommodated in the 
subroutine Userdish to account for non-axisymmetric dishes, parabolic troughs, and linear reflectors. CIRCE is written in FORTRAN, and data input and output are via text files.

Availability and Maintenance

CIRCE is maintained and used by staff at Sandia National Laboratories.

References

- Ratzel, A.C. and B.D. Boughton, 1987, CIRCE.001: A Computer Code for Anaysis of Point-Focus Concentrators with Flat Targets, Sandia National Laboratories, Albuquerque, NM, $\underline{\text { SAND86-1866 (19 MB). }}$

- Romero, V.J., 1994, CIRCE2/DEKGEN2: A Software Package for Facilitated Optical Analysis of 3-D Distributed Solar Energy Concentrators-Theory and User Manual, Sandia National Laboratories, Albuquerque, NM, SAND91-2238 (6 MB).

- Romero, V.J., 2007, New modifications to the CIRCE2/DEKGEN2 solar concentrator modeling package, Sandia National Laboratories memo, August 8, 2007 (modifications include modeling blocking from physical obstructions, modeling isosceles triangle facets, and modeling gore-section facets).

- Sherman, M.P. and V.J. Romero, 2008, Userdish Interpolation Schemes for Modeling NonAxisymmetric Dishes in CIRCE2, Sandia National Laboratories memo, February 15, 2008 (modifications to account for non-axisymmetric dishes).

\subsubsection{SOLTRACE}

As described in Section 2.1.5, SOLTRACE is free software from NREL that can be used to model optical systems for solar power plants, including dish collectors. A Sandia staff member has commented that it is difficult to build an input deck because the coordinate system is not natural to the element. Also, because of the ray-tracing algorithm, simulation times can take much longer (0.5 - 1 hour compared to 20 seconds for CIRCE). See Section 2.1.5 for more details regarding SOLTRACE. Technical support for SOLTRACE is not provided.

\subsection{Dish Receiver}

\subsubsection{AAETES}

\section{Description}

AEETES is a finite control volume numerical model that predicts the thermal performance of receivers (e.g., pool-boiler, heat-pipe) for dish-Stirling systems. Reflux receivers absorb solar energy and use liquid metals to transfer the energy to the heater heads of a Stirling engine. The liquid metal vaporizes on the absorber surface and condenses on the heater heads, releasing the energy before returning to the absorber. AEETES is applicable to axisymmetric geometries with asymmetric incident fluxes. AEETES accounts for radiative and convective heat transfer within the receiver cavity, conductive and convective heat transfer from the receiver housing, and heat transfer to the receiver working fluid. Arbitrary receiver geometries can be specified via planar, 
conical, cylindrical, and spherical sections. Heat losses are characterized by convective, solar and infrared radiation and conductive heat transfer mechanisms. AEETES was validated against an on-sun test using a pool-boiler reflux receiver (Hogan, 1992).

Availability and Maintenance

AEETES is used by staff at Sandia National Laboratories and maintained by the individuals who use them.

References

- Diver, R.B., 1992, Reflux Solar Receiver Design Considerations, in Proceedings of the 1992 ASME International Solar Energy Conference, Maui, HI, April 2-4, 1992, SAND91-1267 (1.3 MB).

- Hogan, Jr., R.E., 1992, AEETES - A Solar Reflux Receiver Thermal Performance Numerical Model, in Proceedings of the 1992 ASME International Solar Energy Conference, Maui, HI, April 2-4, 1992, SAND91-1279C (1 MB).

- Hogan, Jr., R.E., R.B. Diver, and W.B. Stine, 1990, Comparison of a Cavity Solar Receiver Numerical Model and Experimental Data, Journal of Solar Energy Engineering, Vol. 112, p. 183, SAND88-1847C (840 KB).

\subsubsection{FLUENT}

FLUENT is a computational fluid dynamics code that can be used to simulate the thermal performance of dish receiver systems, similar to AEETES. Because FLUENT is a general code, additional features and geometries relevant to dish receiver systems that are already prescribed in AEETES will need to be defined. See Section 2.2.3 for more details regarding FLUENT.

\subsection{Dish Field System Performance}

\subsubsection{Dish Field Systems Model}

An Excel-based software model has been developed by Igo and Andraka (2007) that predicts the annual and monthly energy performance of a field of dish/engine systems. The model accounts for dish-to-dish shading and incorporates the true dish shape, multiple-row shading, and revenue stream models that reflect time-of-day and time-of-year pricing. The model uses meteorological data on yearly or 15-minute intervals and can include local ground slope, stagger between rows of dish systems, and field-edge effects. The model can be used to optimize field spacing and staggering for a given site.

Availability and Maintenance

This Excel-based model is maintained by Sandia National Laboratories. 


\section{References}

- Igo, J., and C.E. Andraka, 2007, Solar Dish Field System Model for Spacing Optimization, in Proceedings of the Energy Sustainability Conference, Long Beach, CA, pp. 981-987.

\section{Summary and Recommendations}

\subsection{Summary of Codes}

A summary of the codes evaluated in this report is provided in Table 1 . The codes are listed in alphabetical order, and a brief description of the code application is provided along with general comments and recommendations.

Table 1. Summary of codes evaluated for CSP technologies.

\begin{tabular}{|c|c|c|}
\hline Code & Application & Comments and Recommendations \\
\hline$\underline{\text { AEETES }}$ & $\begin{array}{l}\text { Axisymmetric dish-cavity } \\
\text { receiver energy-transfer } \\
\text { model }\end{array}$ & $\begin{array}{l}\text { Use as needed. Recommend updating SAND } \\
\text { report with latest modifications. }\end{array}$ \\
\hline ASAP & $\begin{array}{l}\text { General optics code that can } \\
\text { be applied to heliostats, } \\
\text { troughs, linear reflectors, and } \\
\text { dish collectors }\end{array}$ & $\begin{array}{l}\text { Purchase for use with SolidWorks/CosmosWorks } \\
\text { for modeling gravity/wind effects on heliostats, as } \\
\text { well as other collector systems }\end{array}$ \\
\hline$\underline{\text { CAVITY }}$ & $\begin{array}{l}\text { Models energy transfer in } \\
\text { power-tower receiver }\end{array}$ & $\begin{array}{l}\text { No longer used or supported. Commercial codes } \\
\text { such as FLUENT can be used to model power- } \\
\text { tower receiver performance. }\end{array}$ \\
\hline$\underline{\text { CIRCE }}$ & $\begin{array}{l}\text { Optical code for dish systems } \\
\text { (and linear concentrating } \\
\text { systems) }\end{array}$ & $\begin{array}{l}\text { Use as needed. Recommend updating SAND } \\
\text { report with latest modifications. }\end{array}$ \\
\hline DELSOL & $\begin{array}{l}\text { Power-tower system model } \\
\text { and optimization tool }\end{array}$ & $\begin{array}{l}\text { Use as needed. Refine interface and possibly } \\
\text { combine with SOLERGY to develop more } \\
\text { rigorous power-tower system model }\end{array}$ \\
\hline$\underline{\text { DISH-FIELD }}$ & $\begin{array}{l}\text { Dish-field systems model to } \\
\text { optimize layout of dishes }\end{array}$ & Use as needed \\
\hline DRAC/TOPAZ & $\begin{array}{l}\text { Fluid flow and heat transfer in } \\
\text { pipes for central receivers }\end{array}$ & No longer used or supported \\
\hline$\frac{\left(\text { COSM } \frac{\text { FEA }}{\text { OSWORKS, }}\right.}{\underline{\text { ANSYS) }}}$ & $\begin{array}{l}\text { Finite-element analysis codes } \\
\text { for structural and thermal- } \\
\text { stress analyses }\end{array}$ & $\begin{array}{l}\text { Use these codes together with ASAP or CIRCE to } \\
\text { evaluate effects of gravity and wind-induced } \\
\text { deformations on optical performance. Can use } \\
\text { these codes to determine thermal stress on } \\
\text { receiver tubes. }\end{array}$ \\
\hline FLUENT & $\begin{array}{l}\text { Computational fluid dynamics } \\
\text { code for general heat transfer } \\
\text { and hydraulic analyses }\end{array}$ & $\begin{array}{l}\text { Use this code for central receiver performance, } \\
\text { heat transfer in pipes, storage, and solid-particle } \\
\text { receivers. }\end{array}$ \\
\hline
\end{tabular}




\begin{tabular}{|c|c|c|}
\hline Code & Application & Comments and Recommendations \\
\hline GATECYLE & $\begin{array}{l}\text { Models gas-turbine and steam } \\
\text { power cycles }\end{array}$ & $\begin{array}{l}\text { Use together with TRNSYS or other system-level } \\
\text { models to predict power generation of solar } \\
\text { power plants. }\end{array}$ \\
\hline HELIOS & $\begin{array}{l}\text { Models solar flux density from } \\
\text { heliostat fields using cone } \\
\text { optics }\end{array}$ & Use as needed, but not actively supported. \\
\hline IPSEPRO & Models power cycles & Similar to GATECYCLE and STEAMPRO \\
\hline MIRVAL & $\begin{array}{l}\text { Models solar flux density from } \\
\text { heliostat fields using ray } \\
\text { tracing }\end{array}$ & No longer used or supported \\
\hline RADSOLVER & $\begin{array}{l}\text { Models energy transfer within } \\
\text { power-tower receiver }\end{array}$ & No longer used or supported \\
\hline SAM & $\begin{array}{l}\text { System-level software that } \\
\text { can model the performance of } \\
\text { parabolic troughs (and } \\
\text { eventually power towers and } \\
\text { dish/engines) }\end{array}$ & $\begin{array}{l}\text { Can be used to assess system level performance, } \\
\text { but detailed processes (e.g., optics) are not } \\
\text { included. }\end{array}$ \\
\hline SOLERGY & $\begin{array}{l}\text { System-level model for solar } \\
\text { thermal power plants }\end{array}$ & $\begin{array}{l}\text { Refine to allow option for storage or no storage } \\
\text { current versions include one or the other). Revise } \\
\text { interface for possible use with DELSOL to provide } \\
\text { more rigorous power-tower system model }\end{array}$ \\
\hline SOLTRACE & $\begin{array}{l}\text { Optical code for solar collector } \\
\text { systems using ray tracing }\end{array}$ & Free download from NREL, but not supported \\
\hline STEAMPRO & Models steam power cycles & Similar to GATECYCLE and STEAMPRO \\
\hline TBRD & $\begin{array}{l}\text { Dynamic simulation of tubular } \\
\text { receivers }\end{array}$ & Not supported \\
\hline TROUGH HELIOS & $\begin{array}{l}\text { Models optics of parabolic } \\
\text { trough system }\end{array}$ & Not supported \\
\hline TRNSYS & $\begin{array}{l}\text { Modular software for modeling } \\
\text { different solar power systems } \\
\text { and components }\end{array}$ & Used as performance modeling engine in SAM. \\
\hline
\end{tabular}

\subsection{Probabilistic Modeling}

All of the codes evaluated implement deterministic evaluations of the system or component performance, which yield a single value for the simulated output (e.g., LEC). Input parameters are typically entered as specific values rather than distributions of values that honor the inherent uncertainty in many of the system features and processes. As a result, the confidence of the result and uncertainty associated with the results are not reported. The author encourages readers to consider the use of probabilistic approaches to yield uncertainty analyses that can quantify the impact of system uncertainties on the simulated performance metrics. The confidence and likelihood of the simulated metric (e.g., levelized energy cost) being above or below a particular value or range can be readily assessed and presented using these probabilistic methods. In 
addition, sensitivity analyses can be used with probabilistic analyses to determine the most important components, features, and/or processes that impact the simulated performance. This information can be used to guide and prioritize future research and characterization activities that are truly important to the relevant performance metrics.

Uncertainty analyses were performed by Kolb et al. (1994) to evaluate the impact of uncertainties in input parameters on central receiver performance models of levelized energy cost. A screening analysis was first conducted to determine a subset (32) of the hundreds of input parameters that would be assigned uncertainty distributions as opposed to deterministic point values. A stepwise regression analysis was then performed to determine the input parameters that were most correlated to the variability of the simulated performance metric (levelized energy cost). These types of analyses are very powerful and provide additional useful information not available in deterministic analyses. These types of probabilistic analyses should be considered for incorporation into performance models such as SOLERGY or SAM.

As an illustrative example, Figure 7 shows a hypothetical plot of the levelized energy cost (LEC) for a solar thermal power plant calculated using both probabilistic and deterministic methods. In both methods, the LEC was calculated using the simplified equation (Becker and Klimas, 1993):

$$
L E C=\frac{\text { Annualized Capital Costs }+ \text { Annual O \& M Costs }}{(\text { Annual Energy Generated })(\text { Availability })}
$$

In the probabilistic model, each of the four variables in Equation (1) was treated as an uncertain parameter. Each variable is represented by a distribution of values that can be based on data, literature, model results, and/or professional judgment. In this example, a hypothetical uniform distribution was used for each input parameter based loosely on values reported in Becker and Klimas (1993). Equation (1) was calculated 300 times (300 realizations) using randomly sampled values from the distribution of input parameters to yield a distribution of equally probable LEC values. The distribution of calculated LEC ranged from approximately $\$ 0.08 / \mathrm{kWh}_{\mathrm{e}}$ to $\$ 0.16 / \mathrm{kWh}_{\mathrm{e}}$. Figure 7 shows these results as a cumulative distribution function (CDF), or cumulative probability. This plot can be used to predict the probability of the LEC being less (or more) than a particular value, or between two values. For example, in this hypothetical example, there is approximately a 95\% probability that the LEC will be less than $\sim \$ 0.14 / \mathrm{kWh}_{\mathrm{e}}$ and a $5 \%$ probability that the LEC will be greater than $\sim \$ 0.14 / \mathrm{kWh}_{\mathrm{e}}$. There is approximately a $0.9-0.2=0.7(70 \%)$ probability that the LEC will be between $\$ 0.10 / \mathrm{kWh}_{\mathrm{e}}$ and $\$ 0.14 / \mathrm{kWh}_{\mathrm{e}}$.

The deterministic model, using average or "central" values for the uncertain input parameters, predicts an LEC of just over $\$ 0.11 / \mathrm{kWh}_{\mathrm{e}}$, which happens to be the median ( $50^{\text {th }}$ percentile) of the probabilistic model. This single value does not provide any indication of the amount of uncertainty in the output (e.g., that there is a 50\% probability that the LEC will be greater than $\$ 0.11 / \mathrm{kWh}_{\mathrm{e}}$ in this hypothetical example). Also, the deterministic LEC value may shift left or right in Figure 7 depending on the nature of the distributions used for the input parameters (e.g., uniform, normal, log-normal). For example, if most of the input distributions were log-normally distributed, the deterministic LEC value may fall in the $20^{\text {th }}$ to $30^{\text {th }}$ percentile instead of the $50^{\text {th }}$ percentile. 


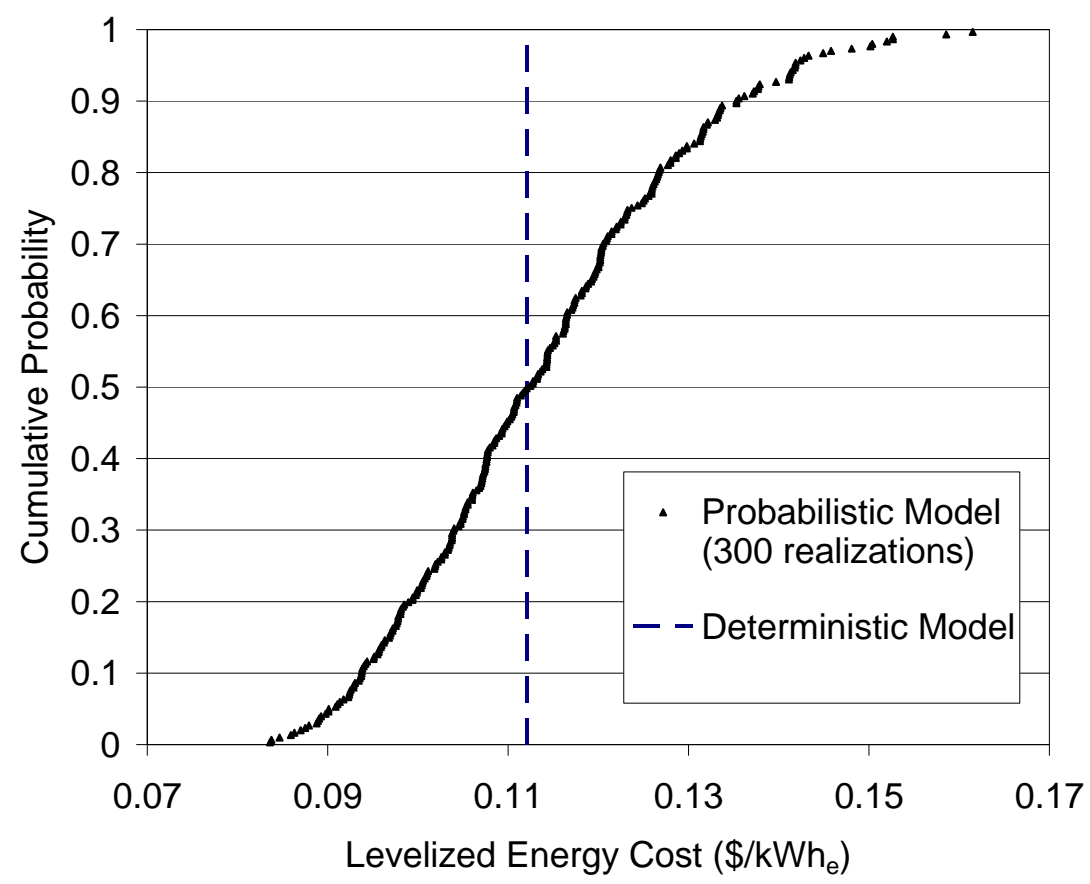

Figure 7. Hypothetical cumulative distribution function (CDF) of levelized energy costs resulting from a probabilistic model with uncertainties in several input parameters. The deterministic levelized energy cost is also shown using the central values for the input parameters.

It should be noted that the number of runs (or realizations) necessary for a random probabilistic (Monte Carlo) simulation increases as the number of uncertain input variables increases. Latin hypercube sampling (LHS) is a method that reduces the number of necessary realizations by ensuring that values are sampled from across the entire input distribution. LHS software has been developed at Sandia National Laboratories that implements this method and allows for correlations among input variables as well (Wyss and Jorgensen, 1998).

In addition to the uncertainty analysis described above, sensitivity analyses can be performed with probabilistic models to identify those input parameters that most impact the simulated performance metric. The sensitivity of the probabilistic model to uncertain input variables can be determined using regression analysis. Multiple regression analysis involves construction of a linear regression model of the simulated output (the dependent variable) and the stochastic input variables (independent variables) using a least-squares procedure. Stepwise linear (rank) regression is a modified version of multiple regression that selectively adds input parameters to the regression model in successive steps (Helton and Davis, 2000). In this method, a sequence of regression models is constructed that successively adds the most important input parameters to the regression to improve the overall correlation. In the end, the sensitivity analysis identifies those parameters that are significantly correlated to the performance metric, and omits those parameters that are not.

Figure 8 shows the results of a stepwise linear regression sensitivity analysis using the 300 hypothetical realizations shown in Figure 7. The sensitivity analysis shows that the simulated 
LEC is most sensitive to the annual energy produced, followed by the annualized capital costs. The availability and annual O\&M costs are much less important in this hypothetical example. Therefore, further characterization and research efforts could be focused on those components and processes that affect the annual energy produced and capital costs, which are shown to have the most impact on simulated LEC in this hypothetical example.

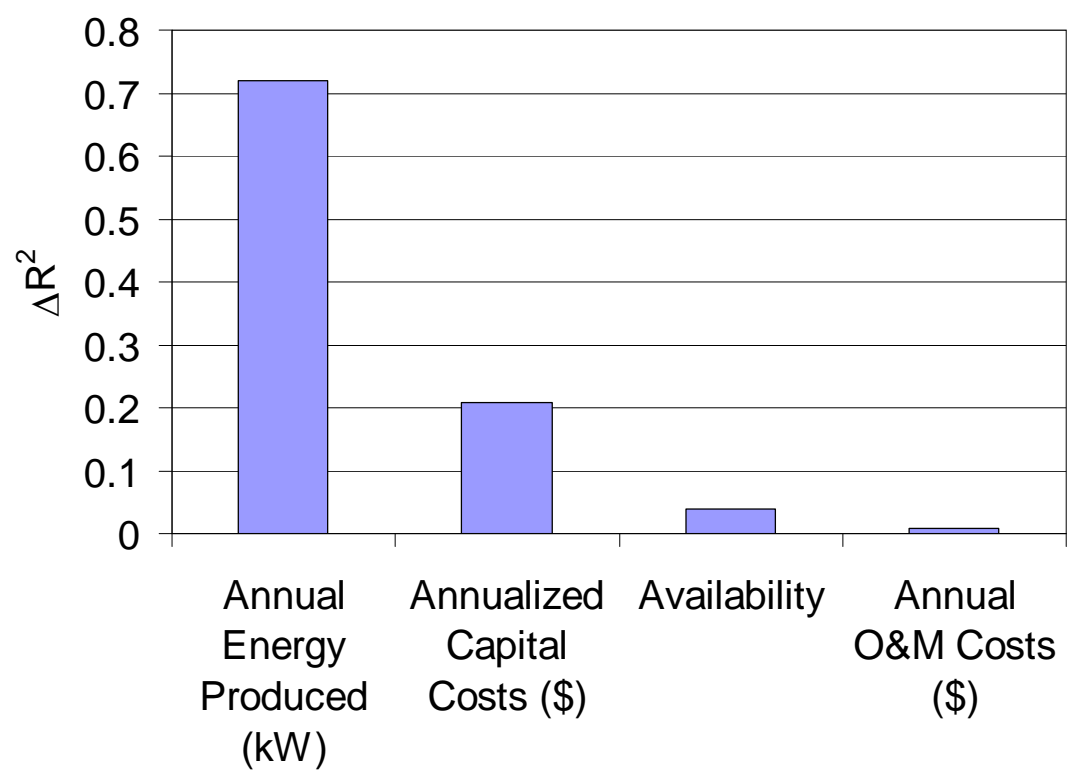

Figure 8. Hypothetical sensitivity analysis showing relative importance of uncertain input parameters on simulated LEC.

In an actual uncertainty and sensitivity analysis, the uncertainty of detailed lower level components and processes (e.g., collector performance, flow rates, heat loss, storage, turbine output, etc.) can be included in the model. In this hypothetical example, the uncertainties of the detailed components and processes are rolled into one of the four high-level parameters defined in Equation (1). For example, all of the uncertainties associated with detailed performance modeling are rolled into the "Annual Energy Produced," and all of the uncertainties associated with component reliability are rolled into the "Availability."

\subsection{Reliability Analyses}

Another important element of performance and economic analyses of concentrating solar power technologies is the reliability of the individual components. The reliability of individual components contributes to the total availability of the power plant, which is a function of the mean time between failures and the mean down time of individual components. Kolb et al. (1994) used UNIRAM (Gardner, 1985) to estimate the reliability of individual components and the total availability in solar power-tower plants. Commercial software also exists to perform many types of reliability analyses for a wide range of applications (see, for example, www.reliasoft.com/products.htm). 


\subsection{Assertion of Copyright}

Many of the codes evaluated in this report were developed in the 1970's and 1980's, prior to the processes now in place that require Sandia to assert copyright of these codes with the Department of Energy. Before these codes can be released to the public, Sandia must request permission from DOE to assert copyright and release the codes. Once this is done, various license agreements can be instituted for the distribution and use of the software (including free software). Complete instructions for the assertion of copyright can be found on the internal (restricted) Sandia website at: http://www-irn.sandia.gov/legal/intellectual/copyright.html.

\section{References}

Abrams, M., 1981, RADSOLVER—A computer Program for Calculating Spectrally-Dependent Radiative Heat Transfer in Solar Cavity Receivers, Sandia National Laboratories, Livermore, CA (SAND81-8248).

Alpert, D.J. and G.J. Kolb, 1988, Performance of the Solar One Power Plant as Simulated by the SOLERGY Computer Code, Sandia National Laboratories, Albuquerque, NM, SAND88-0321 (5 $\underline{\mathrm{MB}}$.

Becker, M. and P.C. Klimas (eds.), 1993, Second-Generation Central Receiver Technologies: A Status Report, Verlag C.F. Muller Karsruhe, Germany.

Dellin, T.A. and M.J. Fish, User's Manual for DELSOL: A Computer Code for Calculating the Optical Performance, Field Layout and Optimal System Design for Solar Central Receiver Plants, Sandia National Laboratories, Livermore, CA, SAND79-8215.

Diver, R.B., 1992, Reflux Solar Receiver Design Considerations, in Proceedings of the 1992 ASME International Solar Energy Conference, Maui, HI, April 2-4, 1992, SAND91-1267 (1.3 $\underline{\mathrm{MB}}$.

Falcone, P.K., 1986, A Handbook for Solar Central Receiver Design, Sandia National Laboratories, Livermore, CA, SAND86-8009 (86 MB).

Gardner, N., 1985, User's Guide for the UNIRAM Availability Assessment Methodology: Version 1.1, EPRI Publication AP-3956-CCN Electric Power Research Institute, April 1985.

Helton, J.C. and F.J. Davis, 2000, Sampling-Based Methods for Uncertainty and Sensitivity Analysis, Sandia National Laboratories, Albuquerque, NM, SAND99-2240 (5.3 MB).

Hogan, Jr., R.E., 1992, AEETES - A Solar Reflux Receiver Thermal Performance Numerical Model, in Proceedings of the 1992 ASME International Solar Energy Conference, Maui, HI, April 2-4, 1992, SAND91-1279C (1 MB).

Hogan, Jr., R.E., R.B. Diver, and W.B. Stine, 1990, Comparison of a Cavity Solar Receiver Numerical Model and Experimental Data, Journal of Solar Energy Engineering, Vol. 112, p. 183, SAND88-1847C (840 KB). 
Igo, J., and C.E. Andraka, 2007, Solar Dish Field System Model for Spacing Optimization, in Proceedings of the Energy Sustainability Conference, Long Beach, CA, pp. 981-987.

Kistler, B.L., 1987, A User's Manual for DELSOL3: A Computer Code for Calculating the Optical Performance and Optimal System Design for Solar Thermal Central Receiver Plants, Sandia National Laboratories, Livermore, CA, SAND86-8018 (10 MB).

Kolb, G.J., 1992, Development of a Control Algorithm for a Molten-Salt Solar Central Receiver in a Cylindrical Configuration, in proceedings of the ASME Solar Energy Conference, Maui, HI, April 5-9, 1992, SAND91-2544C (640 KB)

Kolb, G.J. and ESSCOR Corporation, 1989, Dynamic Simulation of a Molten Salt Solar Receiver, SAND88-2895, Sandia National Laboratories, Albuquerque, NM, 92 p.

Kolb, G.J., J.M, Chavez, P. Klimas, W. Meinecke, M. Becker, and M.Kiera, 1994, Evaluation of Second-Generation Central Receiver Technologies, in Proceedings of the ASME International Solar Energy Conference, San Francisco, CA, March 27-30, 1994, SAND93-2690C (4 MB).

Kolb, G.J and D. Saluta, 1999, Automatic Control of the Solar Two Receiver, in proceedings of the ASME/Solar Specialists’ Conference, Maui, HI, April 12-15, 1999, SAND99-1201C (441 $\mathrm{KB})$.

Leary, P.L. and J.D. Hankins, 1979, User's Guide for MIRVAL - A Computer Coe for Modeling the Optical Behavior of Reflecting Solar Concentrators, Sandia National Laboratories Livermore, CA, SAND77-8280 (microfiche and hard copy available at SNLL).

Ratzel, A.C. and B.D. Boughton, 1987, CIRCE.001: A Computer Code for Anaysis of PointFocus Concentrators with Flat Targets, Sandia National Laboratories, Albuquerque, NM, SAND86-1866 (19 MB).

Romero, V.J., 1994, CIRCE2/DEKGEN2: A Software Package for Facilitated Optical Analysis of 3-D Distributed Solar Energy Concentrators-Theory and User Manual, Sandia National Laboratories, Albuquerque, NM, SAND91-2238 (6 MB).

Romero, V.J., 2007, New modifications to the CIRCE2/DEKGEN2 solar concentrator modeling package, Sandia National Laboratories memo, August 8, 2007 (modifications include modeling blocking from physical obstructions, modeling isosceles triangle facets, and modeling gore-section facets).

Sayers, D.D., 1985, CAVITY-A Computer Code to Couple Radiative Exchange in a CavityType Receiver with the Conductive-Convective Exchange to the Working Fluid, Sandia National Laboratories, Livermore, CA, Internal Memorandum RS 8245/20.

Sherman, M.P. and V.J. Romero, 2008, Userdish Interpolation Schemes for Modeling NonAxisymmetric Dishes in CIRCE2, Sandia National Laboratories memo, February 15, 2008 (modifications to account for non-axisymmetric dishes). 
Stoddard, M.C., S.E. Faas, C.J. Chiang, and J.A. Dirks, 1987, SOLERGY—A Computer Code for Calculating the Annual Energy from Central Receiver Power Plants, Sandia National Laboratories, Livermore, CA, SAND86-8060 (6 MB).

Vittitoe, C.N. and F. Biggs, 1981, User's Guide to HELIOS : Part 1, Introduction and Code Input. A Computer Program for Modeling the Optical Behavior of Reflecting Concentrators, Sandia National Laboratories, Albuquerque, NM, SAND81-1180 and SAND81-1562 (Part 3: Appendices).

Winters, W.S., 1983, DRAC-A User Friendly Computer Code for Modeling Transient Thermohydraulic Phenomena in Solar Receiver Tubing, Sandia National Laboratories, Livermore, CA (SAND82-8744).

Winters, W.S., 1987, TOPAZ-The Transient One-Dimensional Pipe Flow Analyzer: An Update on Code Improvements and Increased Capabilities, Sandia National Laboratories, Livermore, CA (SAND87-8225).

Wyss, G.D. and K.H. Jorgensen, 1998, A User's Guide to LHS: Sandia's Latin Hypercube Sampling Software, Sandia National Laboratories, Albuquerque, NM, SAND98-0210 (560 KB). 


\section{Distribution}

All Electronic Copies:

$\begin{array}{lll}1 & \text { MS-1033 } & \text { C. Hanley, 6335 } \\ 1 & \text { MS-1033 } & \text { C. Cameron, 6335 } \\ 1 & \text { MS-1033 } & \text { D. Riley, 6335 } \\ 1 & \text { MS-1110 } & \text { J. Nelson, 6337 } \\ 1 & \text { MS-1127 } & \text { C. Andraka, 6337 } \\ 1 & \text { MS-1127 } & \text { R. Diver, 6337 } \\ 1 & \text { MS-1127 } & \text { C. Ghanbari, 6337 } \\ 1 & \text { MS-1127 } & \text { G. Kolb, 6335 } \\ 1 & \text { MS-1127 } & \text { T. Mancini, 6337 } \\ 1 & \text { MS-1127 } & \text { T. Moss, 6337 } \\ 1 & \text { Ms-1127 } & \text { N. Siegel, 6337 } \\ 1 & \text { MS-0899 } & \text { Technical Library, 9536 (electronic copy) }\end{array}$

